\title{
Zine Production with Queer Youth and Pre-Service Teachers in New Brunswick, Canada: Exploring Connections, Divergences, and Visual Practices
}

Casey Burkholder

University of New Brunswick

Kate Hamill

University of New Brunswick

Amelia Thorpe

University of New Brunswick

\begin{abstract}
Queer, trans, and non-binary youth navigate school spaces punctuated by erasures, silences, and oppression, and resist these experiences through solidarity-building, activism, and art practice. In this article, we seek to centre experiences of school and society as important
\end{abstract}


spheres of inquiry through participatory visual research with queer, trans, and non-binary young people (ages 12 to 17) and pre-service teachers and community educators (ages 22 to 40) in Fredericton, New Brunswick, Canada. Using an intersectional lens, we consider how intersecting power structures - gender, race, class, and disability - produce unequal impacts in relation to school and social experiences in New Brunswick. Centring youth agency, we position youth as knowledge producers through participatory visual methods of inquiry, including the making of zines (DIY print productions). With youth and pre-service teachers, through inquiry into existing and desired school and social experiences, we seek to make visual the practice of intergenerational solidarity building through zine production.

Keywords: participatory visual research, queer, trans and non-binary youth, pre-service teachers, zines

\section{Résumé}

Les jeunes queers, trans, et non-binaires naviguent dans les espaces scolaires ponctués d'effacements, de silences et d'oppression, et résistent à ces expériences à travers la solidarité, l'activisme, et la pratique artistique. Dans cet article, nous cherchons à circonscrire les expériences scolaires et sociales en tant que sphères d'enquête importantes à travers une recherche visuelle participative avec de jeunes queers, trans, et non-binaires (âgés de 12 à 17 ans) et des enseignants en formation et des éducateurs communautaires (âgés de 22 à 40 ans) à Fredericton, Nouveau-Brunswick, Canada. À l'aide d'une lentille intersectionnelle, nous considérons comment les structures de pouvoir croisées—sexe, race, classe, et handicap_-impactent inégalement les expériences scolaires et sociales des jeunes au NouveauBrunswick. Avec un accent porté sur la capacité d'agir des jeunes, nous les positionnons en tant que producteurs de connaissances grâce à des méthodes d'enquête visuelles participatives, y compris la production de zines (production d'imprimés DIY). Avec les jeunes et les enseignants en formation initiale, à travers une enquête sur les expériences scolaires et sociales existantes et souhaitées, nous cherchons à traduire visuellement la pratique de la construction de la solidarité intergénérationnelle à travers la production de zines.

Mots-clés : recherche visuelle participative, jeunes queers, trans et non-binaires, enseignant en formation, zines 


\section{Acknowledgements}

This work was supported by the Social Sciences and Humanities Research Council of Canada's Insight Development Grant [430-2018-00264]; New Brunswick Innovation Fund under the Emerging Projects Grant [2019-005]. 


\section{Introduction}

Despite protection from discrimination in the New Brunswick Human Rights Act (2011), systematic discrimination of queer, ${ }^{1}$ trans, and non-binary students continues to be prevalent within the local school system (Burkholder \& Thorpe, 2019). The majority of Canadian teacher education programs do not do justice to issues of gender diversity, sexual orientation, or queerness (Airton \& Koecher, 2019), and youth who identify as queer, trans, and non-binary face a higher degree of harassment than other youth in schools (Peter et al., 2016). We first embarked on this study when Casey was preparing for a course called Teaching Elementary Social Studies. She began surveying the existing elementary, middle, and secondary social studies curricula for inclusions of Black, Indigenous, and other people of colour; people with disabilities; and queer, trans, and non-binary people, ${ }^{2}$ and found disappointingly — but perhaps unsurprisingly — that these communities and individuals have been systematically excluded and erased. She found that the existing social studies curricula privileged whiteness, cis-maleness, and heterosexuality. ${ }^{3}$ Later, Amelia undertook an in-depth discursive analysis of the existing curricula and her results confirmed Casey's preliminary findings: queer, trans, and non-binary people and communities had been completely erased from New Brunswick social studies curricula. These erasures point to the enduring legacy of heteronormativity in the public schooling system.

School environments - within our context of Fredericton, New Brunswick - operate under heteronormative assumptions, wherein students' gender, gender identity, and sexuality is assumed to be cisgender and heterosexual. Such assumptions, obviously, disproportionately affect youth who are queer, trans, and non-binary (Strear, 2015).

1 In our work, "queer" refers to a spectrum of sexual and gender identities. We are compelled to use the term "queer" throughout the article, drawing on the work of Michael Warner (1993) who suggested, "The preference for 'queer' represents, among other things, an aggressive impulse of generalization; it rejects a minoritizing logic of toleration or simple political interest-representation in favor of a more thorough resistance to regimes of the normal" (p. xxvi).

2 Of course, we acknowledge that people experience multiple categories of difference, and we point to Wolastokiyik artists and activists, such as Indigo Poirer and Jeremy Dutcher, as examples of those whose identities are at the intersection of matrices of oppression, highlighting how their activism and the civic contributions of their communities and ancestors have been erased from inclusion in compulsory schooling curricula. We also note that both Poirer and Dutcher are young people, and that we have few historical examples to draw upon in this note as their contributions have been minimized and/or erased.

3 New Brunswick's social studies curricula can be downloaded here. 
Heteronormativity and cisnormativity are fostered in the school environment through local spaces, such as binary washrooms; gender inclusive washrooms are the exception not the rule in New Brunswick school and social spaces. In a piece of architectural criticism about public washroom spaces, trans people, and cisnormativity, poet Lucas Crawford condemns the ways in which transfolk and non-binary people are policed, monitored, and rendered suspect in washroom spaces. We suggest that Crawford's (2020) words are prescient in response to school washroom spaces as well:

While most transphobic bathroom bill supporters premise their campaigns on the protection of innocent young girls, let me - and Tribe 8 - tell you that women in women's washrooms enforce gender norms with the best of them. Tribe 8's rhyme captures the very common scene succinctly: "Excuse me sir! / Over by the stall! / Wrong fucking bathroom! / The men's is down the hall!" [3] In the surveys she collected for Queering Bathrooms, Sheila Cavanagh reports that trans people tend to be policed in bathrooms not only for appearance, but for many things. Her respondents describe cisgender people commenting on matters ranging from the sound of one's urinary stream to the direction of one's feet when sitting on the toilet [4]. In short, cisgender people do not understand boundaries. (para. 3)

School-based heteronormative pedagogical practices can also look like teachers' tendency to sort boys into one group and girls into another, or the practice of employing gendered language (e.g., "ladies and gentlemen"; "boys and girls"). Heteronormativity and cisnormativity are likewise reinforced throughout the formal curricula. Looking deeply into New Brunswick's social studies curricula, we noted that all important actors are portrayed as white, male, and straight. Heteronormativity and cisnormativity are also enforced through school-based policies and practices, including dress codes and the ways that school practices often minimize instances of homophobia and transphobia. As such, heteronomativity and cisnormativity within schools must be challenged at the structural level ( $\mathrm{Ng}$ et al., 2019). Because of the pervasiveness of heteronormative and cisnormative discourses, policies, and practices, many queer, trans, and non-binary youth feel disconnected from their schools (Wilson et al., 2018). Schools also perpetuate heteronormativity and binary gender systems through the hidden curriculum - a consequence of socialization that takes place within the school environment (Halstead \& Reis, 2003). The gendered hidden curriculum provides youth with a cultural definition or script of gender, and 
presupposes sexual, personal, and societal expectations that they ought to attain (Hernández et al., 2013).

Heteronormative policies and practices within schools encourage interpersonal and structural violence against queer, trans, and non-binary youth (Hall et al., 2018), who often experience gender-based harassment and violence within their schools. Efforts to address this type of harassment and violence often minimize it and mischaracterize it as bullying - downplaying the severity of violence and harassment within schools does not foster a safe environment (Singh \& Kosciw, 2017). Szalacha (2004) argues that there is a need for queer school environments in order to make queer, trans, and non-binary youth feel more comfortable, and that the lack of inclusive school environments for queer, trans, and non-binary youth mirrors the prevailing cultural values outside of the school. In acknowledging the ways in which policies to promote inclusion often separate and stigmatize queer youth, we draw on the work of Jen Gilbert (2014), who suggests that schoolbased inclusion practices — such as Gender Sexuality-Alliances (GSAs) — are in practice often "politically correct but conceptually flawed" (p. 6). Queer, trans, and non-binary identifying students may feel unwelcome at school and excluded from the larger community (Graff \& Stufft, 2011), despite being provided with tokenistic spaces and places to gather.

We push back against policies and practices that promote gender-based harassment within schools, and highlight the resilience of the seven queer, trans, and non-binary youth that we are working with in the context of Fredericton, New Brunswick, Canada. The youth we work with continually resist violence in their schools and with wider society, and they oppose the minimization of their experiences and knowledge about the world. These youth are also constantly engaged in art-making, activism, and working to build collectives in order to address the existing conditions in school and society. In this article, we begin by describing a zine-making (do-it yourself print production) workshop in January 2019 with seven queer, trans, and non-binary youth where we highlight their capacities as knowledgeable agents and resilient humans who live, study, thrive, and create in response to school and social conditions.

The study also focuses on a second workshop in February 2019 with seven pre-service teachers who created zines in response to the queer, trans, and non-binary young people's zines. We were interested in working with pre-service teachers through a lens of youth resilience in an effort to confront some of the existing literature that 
suggests that teachers and school administrators are consistently trained to support queer, trans, and non-binary youth through a deficit lens that focuses on victimization, rather than one celebrating their resiliency and acknowledging the systems at large that oppress them (Jones, 2013). In this article, we ask, What can we learn about the school and social realities of queer, trans, and non-binary youth and pre-service teachers in New Brunswick, Canada, by engaging with their zines? What visual practices do the youth and pre-service teachers employ, and what thematic divergences and convergences are explored through the zines?

\section{Positioning Ourselves in Relation to the Study}

We write together as three white, middle-class, cisgender women (one queer, one bi, one straight) who have commitments to educational and social reform in the context of New Brunswick. Casey is an associate professor who teaches and researches in the area of gender, sexuality, participatory visual research, and social studies education. She is also a parent and is becoming increasingly reminded of, and concerned by, the compulsory heterosexism that begins in early childhood settings and pervades all of the levels of compulsory schooling. Her commitments to educational and social change are political, and are drawn from her embodied and internalized experiences of homophobia from her own early educational experiences. She writes and works in solidarity with the youth with whom she works, and out of a desire to make systemic change for these participants and those who will follow them in New Brunswick schools - including her own child.

Katie is a doctoral student who primarily researches human rights education, intersectionality, and participatory visual research. Through all of her work, she aims to shed light on the various forms of oppression contributing to an inequitable New Brunswick, and to promote social change through education.

Amelia is a doctoral candidate at the University of New Brunswick and the co-chair of Fierté Fredericton Pride. Her research is centred on identity, language, and connectivity within sexual and gender minority communities. Amelia has extensive experience working with queer, trans, and non-binary youth. She has worked with numerous not-for-profit and advocacy groups in three provinces, and brings her experience in education, policy, advocacy, and community support to the study. 


\section{Context}

Classrooms are sociocultural spaces influenced by students, the school administrators, teacher practices, and curricula. Within New Brunswick, and in most of North America, school environments operate as though students are heterosexual and fit within prescribed gender binaries (Dinkins \& Englert, 2015). School spaces must be changed—discursively, socially, and physically - to consider the lived realities and needs of queer, trans, and non-binary students more thoughtfully, and to push back against toxic masculinity (Rands, 2009). Teachers' assumptions about sexuality and gender contribute to the perpetuation of systematic oppression, and also have a significant influence on how youth shape their identities and sense of self in the classroom. However, teachers have reported feeling hesitant to provide open support for queer, trans, and non-binary students because of the potential backlash among parents, or within the school (Payne \& Smith, 2014). Engaged social supports - in relation to physical, social, and discursive spaces-are essential in creating less violent, less homophobic, and less transphobic school spaces.

\section{Theoretical Framework}

The study takes as its methodology a participatory visual research framework, which is rooted in intersectional feminism (King, 2016), to help understand queer, trans, and non-binary youth engagement with concepts of existing conditions and desired school and social futures. Our context, participants, and research team are overwhelmingly white, and so we seek to engage with critical race-informed approaches to queer theory (Smith, 2010) to confront the unrepresentative whiteness of our study and context. Our understanding of participatory visual research with young people draws on the critical work of Eve Tuck and K. Wayne Yang (2014), whose discussion of youth as a discursive category encompasses "structural (and historical, generational, political) location...a legally, materially, and always raced/gendered/classed/sexualized category around which social institutions are built, disciplinary sciences created and legal apparatuses mounted" (p. 22). We also draw on the work of Hiram Perez (2005) in our approach to queer theory, noting, as Perez did, that "queer theory, when it privileges difference over sameness absolutely, colludes with institutionalized racism in vanishing, hence retrenching, white privilege. It serves as the magician's assistant to whiteness's disappearing act" (p. 187). 
Working primarily with white queer youth (six of the seven youth participants) and white pre-service teachers (all seven of the seven pre-service teacher participants), we call attention to whiteness in our research context.

Intersectionality as a theory and method works to identify and dismantle interlocking systems of oppression (Crenshaw, 1989); through this lens, we consider the situated, specific, and relational nature of social power, and how social relations shape and are shaped by environmental factors (Sturgeon, 2016; Thompson, 2016) - including schools. Attending to the embeddedness of historic and ongoing legacies of slavery and colonialism within the exploitative and extractive practices of late-stage capitalism (Preston, 2017) in the context of New Brunswick, as well as in the context of heteronormativity, we explore school and social experiences, past and present, with a focus on queer, trans, and non-binary youth, and resistance through zine production with queer, trans, and non-binary youth and pre-service teachers. Specifically, we focus on an intersectional analysis (Crenshaw, 1989) of the contemporary and historic queer stories shared in the youth and pre-service teachers' zines, which touch on subjects such as gender-based violence in schools, presumed and enforced heterosexism, and navigating dating and relationships while both young and queer.

\section{Zine Production and Visual Culture Practice}

Zines are a form of self-expression that are simple and inexpensive to produce (O'Brien, 2012). Zines have been seen as a critique of mainstream media production that typically excludes youth perspectives and provide space for marginalized voices - including queer, trans, and non-binary youth (Chu, 1997). Casey came to make zines through her engagement with riot grrrl cultures (Rosenberg \& Garafalo, 1998), through the art and activism of Kathleen Hanna, and throught the work of other primarily white feminist punks as a teenager growing up in Alberta in the 1990s. O'Brien (2012) refers to zines as a kind of social currency that is circulated by hand, while Buchanan (2012) suggests that zines are often visually appealing and present narratives that make visual people's everyday experiences. There is a "radical potential [in] self-publishing, [including] the capacity for zines to spread political resources, help start movements, or create subcultural communities across long-distances" (Burke, 2018, para. 2). Zines can be created independently or as a group, and they are a part of the do-it-yourself (DIY) cultures that took off during the 
1980s as a means for marginalized folks to share their stories and build communities in an informal manner (Buchanan, 2012; Creasap, 2014). As is inherent to DIY work, there is no wrong way to make a zine. Alison Piepmeier (2008) describes zines as "quirky, individualized booklets filled with diatribes, reworking of pop culture iconography, and all variety of personal and political narratives" (p. 214). Zines often display mixed media and collage in a manner that creators consider cathartic to make (Etengoff, 2015; Piepmeier, 2008). Zines also help youth make connections between theory and everyday life (Creasap, 2014). The physicality of zines provides a different kind of sharing and distribution that can create communities different than those that youth engage with online (Creasap, 2014). Zines are an inherently queer literacy practice, and have a queer sensibility that "can disrupt linear repro-time and space, and ways of making archives" (Lymn, 2014, p. 1), as they destabilize hierarchies and challenge hegemonic archival practices.

\section{Zine-Production within a Participatory Visual Research Framework}

We highlight zine production within a participatory visual research framework, as we ground the project in ethical concerns about queer youth resilience and the importance of embodied and material representation of queer youth identities. By engaging with participants' existing art practices (drawing, collage, writing), by conceptualizing zine making as a queer archiving and exhibition process, and by simultaneously employing participant-produced visual tools, people can help to share the diversity of queer, trans, and non-binary youth-led political activism through their zines (Gubrium \& Harper, 2013; Mitchell, 2011). Zine production as a participatory visual research process encourages participants to speak back to discourses, practices, and policies that affect their lives (Mitchell et al., 2017) by telling their own stories in their own voices with DIY aesthetics. However, participatory visual researchers have only begun to probe the notion of what it means to bring a participatory ethos - including the perspectives of participants who generated the zines and the audiences who consume them (Rose, 2012) - to modes of exhibition and archiving (notable exceptions include Burkholder, 2016; Burkholder \& MacEntee, 2016; Burkholder \& Thorpe, 2019; Lymn, 2014). As such, this study seeks to contribute to the literature on archiving participatory visual research by highlighting the ways that zines produced by queer, trans, and non-binary youth and pre-service teachers 
might be shared and disseminated as forms of political activism in their communities and in the digital realm.

In what follows, we first describe a research workshop called Where Are Our Histories? in which we engaged seven queer, trans, and non-binary youth in zine production. The workshop was one in a monthly series that Casey and Amelia held at the University of New Brunswick between December 2018 and February 2020. We also describe a follow-up workshop with seven pre-service teachers and community educators called Queering New Brunswick Social Studies, where the adult participants responded directly to the zines produced by the queer, trans, and non-binary youth.

\section{Methods: Where Are Our Histories? Zine Production Workshop}

In December 2018, we began a series of monthly arts-based workshops with queer, trans, and non-binary youth (ages 13 to 17) in Fredericton, New Brunswick, Canada. The project began in order to investigate the erasures of queer histories from New Brunswick social studies curricula and classrooms, and grew to encompass young people's school and social experiences more broadly. The initial December 2018 workshop centred on stencil and cellphilm making (for cellphone + film production, see MacEntee et al., 2016) that prompted the youth to think about the question, "Where are our [queer] histories?" We created a series of short cellphilms that described both the ways in which queer, trans, and non-binary youth experienced instances of violence and exclusion, and how they resisted these spaces and policies and sought to demand change. One of the results of the cellphilm and stencil workshop was that the young people wanted to keep meeting and making art together in subsequent workshops. From January 2019 to February 2020, we met in monthly arts-based workshops, where the membership fluctuated between three and seven members. In January 2019, we - seven youth, Casey, and Amelia-met and produced zines and buttons in a three-hour workshop. 


\section{Findings}

In this section, we describe the points of intersection, common themes, and divergences in an analysis of five zines produced by queer, trans, and non-binary youth who were promoted to think about "queering their school experiences," in the January 2019 zine workshop. We then analyze two zines produced by pre-service teachers in the February 2019 workshop in response to the young people's zines, and one zine produced by a member of the research team (Amelia) in response to her discursive analysis of all the $\mathrm{K}-12$ social studies curricula seeking representation of queer, trans, and non-binary citizens and communities. We organize what follows by zine title, providing our analysis about the zine's aesthetic and thematic qualities. We note that the three-part zine Breaking the Binary (Figure 1) deals with suicidal ideation, which we discuss in our analysis below.

\section{Queer, Trans, and Non-Binary Youth-Produced Zines}

Breaking the Binary: Part 1, Part 2: Timeline A \& Timeline B. Raven's Breaking the Binary, drawn with black marker, takes up the genre of a comic strip. The zine is told in three parts. Part 1 of the zine illustrates the story of an individual refusing to check either the box "male" or "female" while filling out a form and instead writing "none of the above." Part 1 concludes by showing the character being rejected for insurance because they "failed to choose a gender." The comic shows the character crying while another character yells, "Choose a gender!!" at them. The next part of the zine is broken up into two separate timelines that each take up the character's possible responses to the need to "choose a gender." Part 2's Timeline A (see Figure 1, below) shows the character alone on the cover and then alone in a series of panels. The character laments, "This world always enforces the gender binary," and the story ends with the character dying by suicide. Part 2's Timeline B offers another take on how the non-binary character might respond to the challenge posed at the end of Part 1. In Part 2's Timeline B, the protagonist is depicted in a community and has people standing in solidarity behind them. The zine uses the same line of dialogue, "This world always enforces the gender binary," but this time the protagonist is depicted as part of a larger community, with others standing alongside them as they protest the gender binary together. In our analysis of the zine, we were struck by the fact that Raven considered the two outcomes put forth in Timeline A (dying 
by suicide) and Timeline B (engaging in protest and activism) as potential responses to dealing with the gender binary that the protagonist confronts in the world. We note that experiences of the gender binary are perpetuated in school spaces - both physical spaces, like washrooms, and in discursive space through teacher and youth formal and informal talk and text.

\section{Figure 1}

Breaking the Binary: Part 1, Part 2: Timeline A \& Timeline B
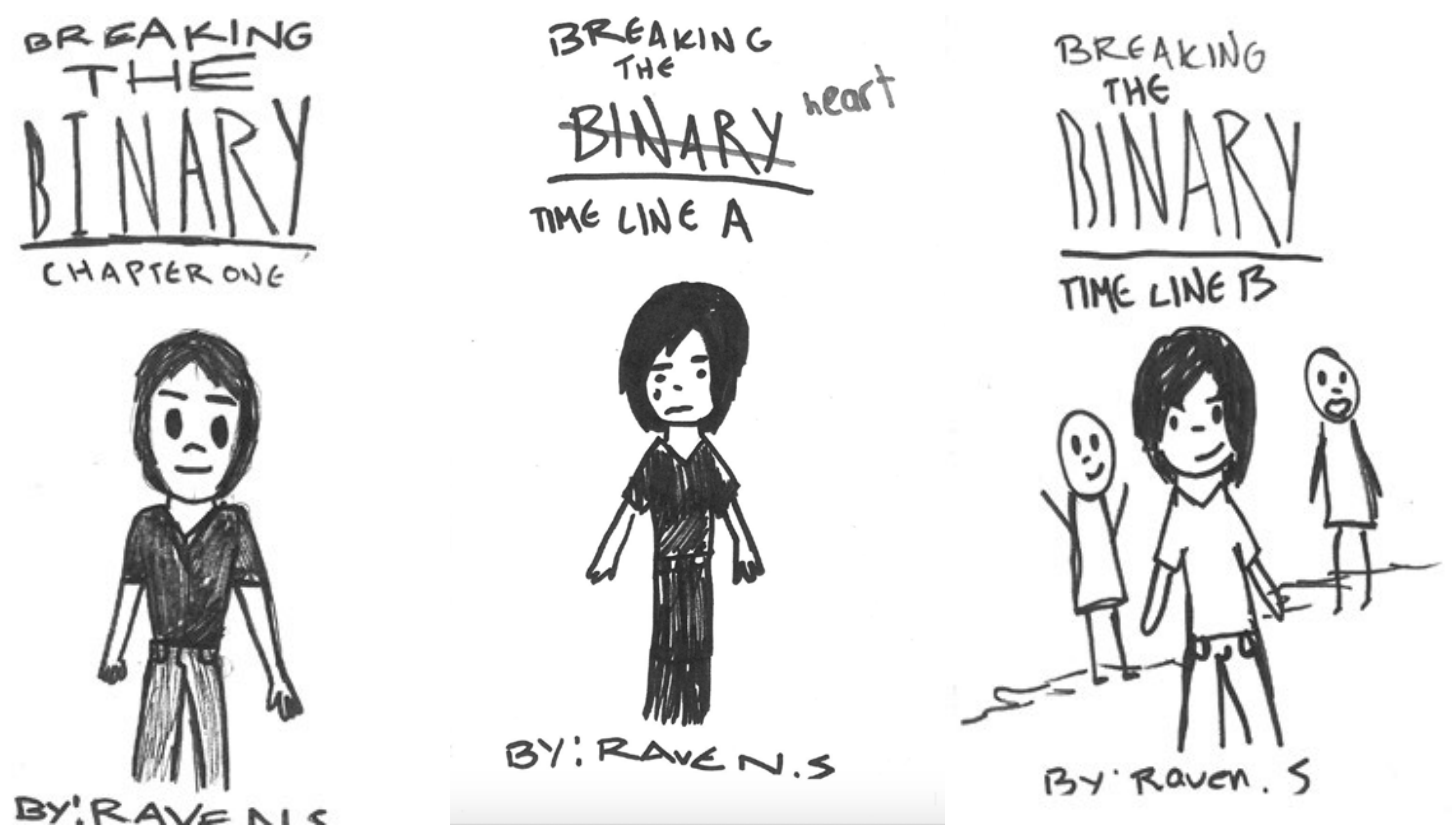

Boring Stuff. Jay's ${ }^{4}$ zine (Figure 2) is written and drawn in pencil, creating lighter lines on the photocopied zine. An illustration of a person saying "These just don't interest me" graces the cover of the zine. At the end of the zine, Jay writes that the zine was created because he needed to feel passionate toward something, and he goes on to list a variety of passions including school and writing. Jay's zine reminds us that the young people's experiences must not be homogenized. Although others in the workshop were politically engaged and active, Jay's zine describing boredom and lack of interest is an important example of a kind of youth resistance. As Eve Tuck and K. Wayne Yang (2014) note in

4 Participant's chosen pseudonym. 
their book on youth resistance, "youth resist educational injustice in multiple, sometimes simultaneous and contradictory, sometimes self-injuring, sometimes triumphant ways" (p. 2). Jay's desire to create a zine in defense of "boring stuff," and writing and drawing about how things just don't interest him, struck us as a great example of resistance, not just to his school and social experiences, but also to the workshop space and the zine prompt itself.

\section{Figure 2}

\section{Boring Stuff}

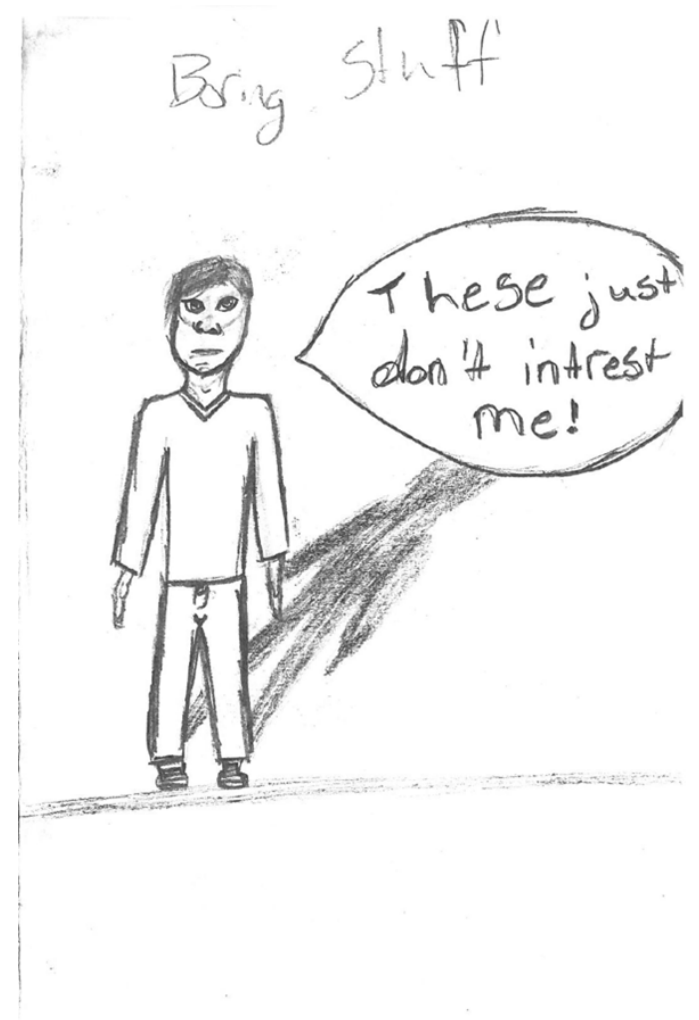

Harmless? Olivia's zine (Figure 3) combines collage (through cutting and pasting) with drawing and writing in marker. She uses a combination of cut and paste words and storytelling to describe her feelings about climate dystopia and the call to youth action. The story she presents through marker drawn over a dark collage of a map with buildings over top, displays themes of wanting to escape, expressing that things will be better in the future, and feeling as though she cannot truly express herself. Olivia asks, 
"Why can't I describe how I feel?" and "Is it important or is it just there?" The final page of the zine asks, "Who even cares?" In reflecting on the zine, we were struck by the DIY aesthetic that Olivia used in order to articulate her feelings of discomfort, isolation, and the desire to resist these feelings and to work toward living in an uncertain future.

\section{Figure 3}

Harmless Zine: Who Even Cares?

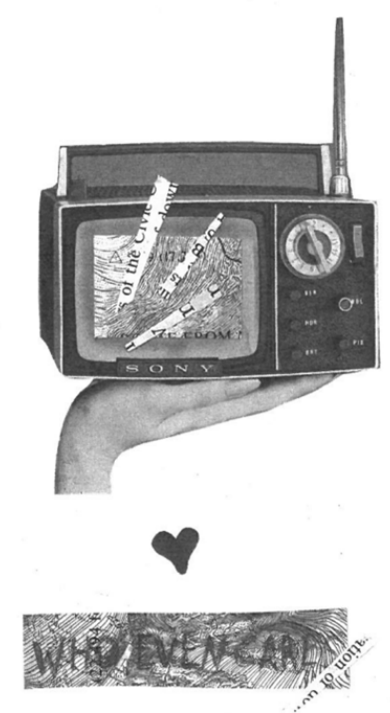

Bi PEOPLE Exist!! Rae's zine (Figure 4) combines cut and paste, drawing, marker, and writing. This zine includes cut and paste imagery of phrases that demonstrate themes such as wanting to escape, in examples like "Take me with you in grasses" and "Hold on for the arrival of death." There is also a drawing of a person and collaged images of nature and greenery. Over top of these images, in marker, Rae has written "bisexuality" and "it's not confusion" and "end bisexual erasure" amongst a repeated pattern 
of drawings. Through this zine, we believe that Rae was articulating that in a search for a queer identity, and in entering queer spaces, they wanted to articulate that their bisexuality was valid, and that they deserved recognition and space, despite feelings of erasure.

Figure 4

Bi PEOPLE Exist!!

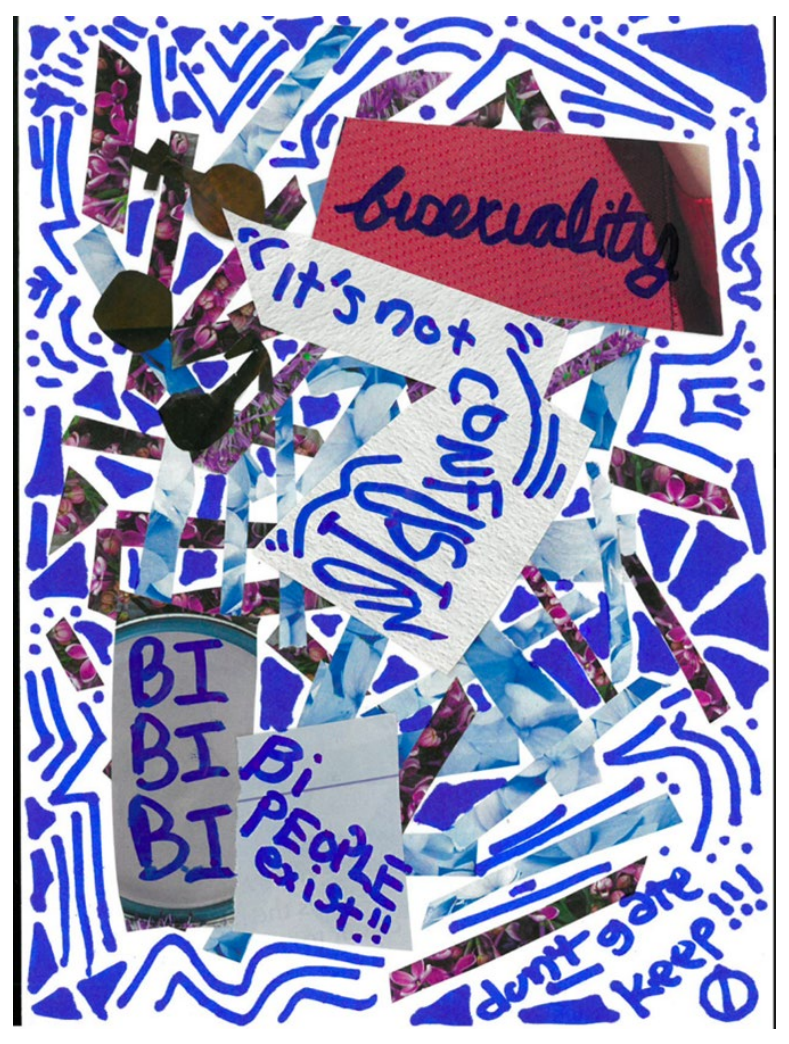

The Lonely Eternity. Raven's second zine-unconnected to the Breaking the Binary storyline (see Figure 1) — combines collage, pencil, writing, and marker to discuss feelings of heartsickness and experiences with love. The zine combines marker and cut and pasted images with the words "the lonely eternity" at the fore. Aesthetically, the zine combines a collage of faces, buildings, greenery, and animals. Laid out on top of the images are cut out words such as "hope" and "miracle." Further writing on the zine describes love as a universal feeling that is both beautiful and painful. We see a link between Raven's The Lonely Eternity and Olivia's Harmless? as they both take up 
the potential, excitement, and fear that accompanies first loves (both consummated and unrequited).

\section{Reading the Youth-Produced Zines Together}

Throughout the queer, trans, and non-binary youth-produced zines, we noted aesthetic and thematic connections. The zines used drawings, hand-writing, collage, and re-mixed images in order to share experiences of frustration, loneliness, heartsickness, boredom, love, resilience, solidarity, calls for representation, and resisting erasures. Despite prompting the youth to think about "queering their school experiences," a surprising finding was that none produced zines focused on school, but rather highlighted the relationships that happen within and beyond schools, as well as the ways that they experience structures as queer, trans, and non-binary youth. Taken together, the zines offer nuanced ways of examining youth experiences, and the zines themselves - once disseminatedprovide tangible actions to queer and identify the complexity of understandings of the issues and experiences of queer, trans, and non-binary youth in our context. The zines demonstrate that the young people seek to break the gender binary and find belonging amongst conservative social and structural spaces. Stories shared in the zines express wanting to escape alongside hopeful sentiments that the youth imagine better futures. However, we also note that the youth and their experiences are as different as their zines. We continue to explore questions such as: What might a non-homogenizing approach to including their diverse identities and experiences look like within a school-based context? Where are there spaces within the classroom, within the school, and within the larger community to accommodate these young people and their ideas about existing and desired conditions for queer, trans, and non-binary youth?

\section{Queering New Brunswick Social Studies Workshop}

In January 2019, Casey put out a workshop call-for-participants amongst the pre-service teachers in the Bachelor of Education program at her university. In this call, she described that the workshop would focus on art production in response to the erasure of queer histories in New Brunswick social studies classrooms. Seven participants responded and attended a two-day workshop in February 2019. At the workshop, we created stencils, zines, and short cellphilms; in this section of the article, we focus our analysis on the 
zines that the pre-service teachers produced. We (Casey and Amelia) began this workshop by sharing the queer, trans, and non-binary youth-produced cellphilms Nackawic Needs a GSA NOW!!, Coming Out, and Gendered. We then shared the five youth-produced zines: Jay's Boring Stuff, Olivia's Harmless?, Rae's Bi PEOPLE Exist!!, and Raven's two zines, The Lonely Eternity and the three-part Breaking the Binary. The pre-service teachers read these zines and then produced their own in response. In what follows, we engage in a close read of each of the pre-service teacher-produced zines.

\section{Pre-Service Teacher-Produced Zines}

Teachers Need Queer Resources. This collaborative zine combines cut and paste, drawing, and writing. The creator seeks to bring queer activism and histories to the curriculum and wrote that doing so is an ethical practice. The zine includes a drawing of an individual asking how a teacher can be ethical in their practice and concludes that they must make space and work alongside communities. The zine features cut and paste letters that spell out "queer histories matter" and shows pictures that have been partially covered with black marker.

Women vs. No Man Lands. This zine combines cut and paste, marker, and writing. It explores the considerations of new teachers and what they wish they had learned in school, and explores how new teachers can work within the binary gender system. In the zine, the teachers state that they wish they had been taught in school that individuals do not have to fit within the gender binary of male or female but they are free to be themselves. Instead, youth are taught that men do things while women watch. The zine ends with the statement, "End queer fear."

\section{Research Team-Produced Zines}

At the same workshop, the research team, Casey and Amelia, created zines in response to the youth-produced zines. We share a zine that Amelia prepared to disseminate some of the findings relating to a discursive analysis of the existing $\mathrm{K}-12$ social studies curriculum in New Brunswick. We analyze the pre-service teacher-produced zines and the research team-produced zines together. 
Curriculum Examination. Amelia's zine (Figure 5) combines marker and writing. The zine discusses that girls' and women's stories are missing from the existing New Brunswick social studies curriculum; there is one mention of queer people within the curriculum, amongst 19 curriculum documents surveyed. The zine makes visual the discursive analysis that Amelia conducted, and lists key words that are missing in such documents: trans, non-binary, gay, girl gender, lesbian, women, bisexual, female, sexuality, queer. The zine asks, "Where are these voices?"

\section{Figure 5}

Curriculum Examination

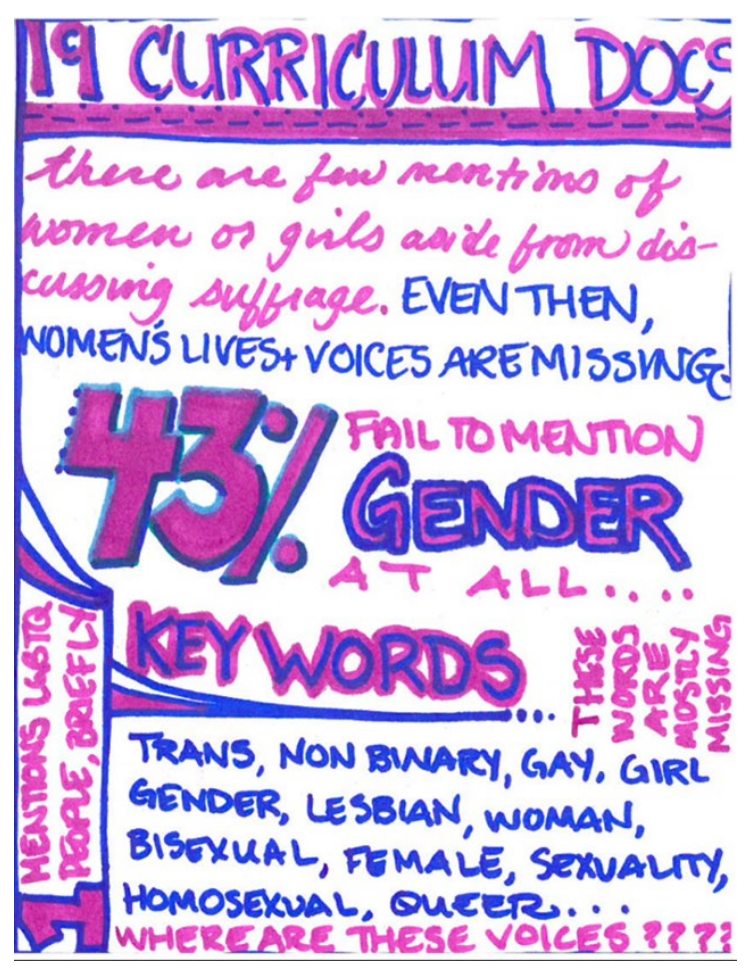

Queer Histories Matter. The following zine (Figure 6) incorporates cutting and pasting to create a colourful collage reading, "QUEER HISTORIES MATTER.” In the interior of the zine, Casey includes a drawing of herself and a large speech bubble that reads, "Bringing queer histories and activism to schools is ethical practice." In the final page of the zine, Casey explains that in her estimation, ethical teaching works in 
solidarity with queer, trans, and non-binary communities and in support of the queer, trans, and non-binary young people navigating unsafe school and social structures.

\section{Figure 6}

Queer Histories Matter

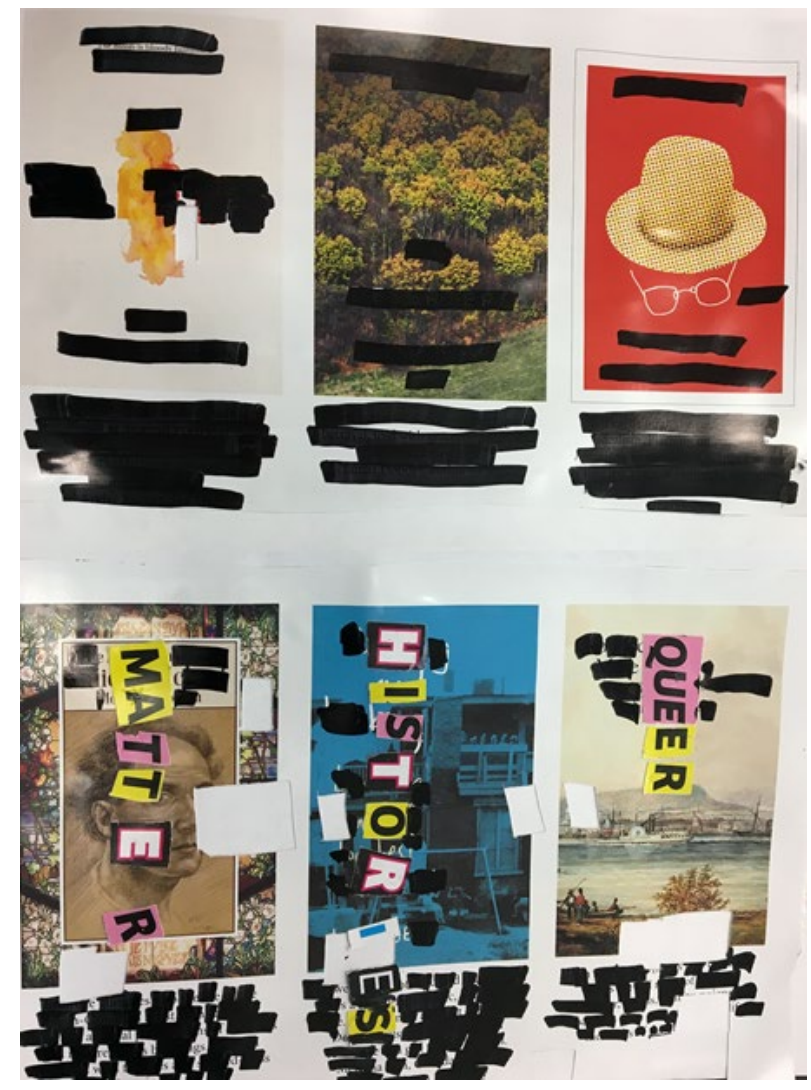

\section{Reading the Pre-Service Teacher- and Research Team-Produced Zines Together}

Taken together, the zines vary aesthetically in relation to the visual practices used: marker, writing, drawing, collage, and cutting and pasting. The pre-service teacher zines demonstrate that pre-service teachers question where queer voices and histories are in the curriculum. Like the youth participants, the pre-service teachers' and research team's zines demonstrate themes of belonging, love, queerness, and challenging the gender binary. The zines also demonstrate that teachers seek support for disrupting the binary 
gender system and heteronormativity within the school system. The zines indicate that teachers are wondering how to be advocates within the school system, that they wish to be allies for queer, trans, and non-binary youth, and that they are unsure as to how they can combat heteronormativity within schools. As we note in our analysis of the queer, trans, and non-binary youth zines, young people did not reference school directly in their zines. However, the pre-service teacher- and research team-produced zines focused on schools as a site to resist and push back against queer, trans, and non-binary youth exclusions, and support their understanding of the needs and desires of the young people. We note the thematic disconnect here, even as the pre-service teachers and the research team began creating zines in response to the youth-produced zines. We see, as Burke (2018) notes, the radical potential for zines to spread resources, to offer space for people to share their own ways of knowing in familiar and new text making, and to encourage sharing across communities and age groups.

\section{Moving Toward Dissemination and Social Action}

Zine production with queer, trans, and non-binary youth and pre-service teachers provides a DIY approach to knowledge production, and zines themselves, as short, powerful texts, provide ways of disseminating knowledge among the communities that they affect. By employing participatory visual research methods, we highlight the ways that creative knowledge dissemination through zine production can promote youth solidarity and local and school-based activism by connecting youth and pre-service stories with larger audiences. As Jessie Lymn (2014) suggests, zines themselves have a "queer sensibility and this 'zine' sensibility can disrupt linear repro-time and space....and ways of making archives... [through] formal collecting institutions, bedrooms, do-it-yourself archives in social centers and cafes, scholarly publications and zine anthologies" (p. 1).

We see disseminating the visual products among youth as a methodological opportunity for the study of, and a contribution to the literature on, participatory visual research relating to dissemination of knowledge produced by research participants (Burkholder \& Thorpe, 2019). Our work contributes to a way of disrupting the erasure of queer, trans, and non-binary youth within schools and social studies curricula by sharing their zines with pre-service teachers and community educators. We note that when the pre-service teachers and research team created zines in response to the queer, trans, and 
non-binary youth-produced zines, they all centred the school as a site to support young people. However, the young people's zines did not directly discuss schools. In this way, we chose to read and create in response to what we wanted to see, or the context that we felt spoke most directly to us, rather than focusing on the young people's identified themes.

From this finding, we suggest that it might be useful to provide specific strategies in facilitating analysis, exhibition, and dissemination of the youth- and pre-service teacher-produced zines to outside audiences (teachers, students, readers, policy makers). In reflecting on the ways that we did not really "listen" to what the youth suggested in their zines, we realized that the zines themselves might need to be introduced to other audiences by providing context and strategies to support their reading. We see our failure as productive (Nairn et al., 2005), as we have sought to address our own analytical preferences and thought through how we might move forward in disseminating these works. Having experienced this failure, we hope to make changes to our research design and facilitation processes by developing specific exhibition strategies by and for queer, trans, and non-binary young people to exhibit the visuals they made in order to delve more deeply into complex understandings of their experiences, rather than reading them exclusively through the lens of our own experiences.

In a SSHRC-funded project that Casey and Amelia are currently working on, Pride/Swell, the primary focus of the project is to provide queer, trans, and non-binary youth in Atlantic Canada with art supplies and prompts about their identities, sense of belonging, and community, and work with these youth, at a distance, in order to think explicitly about how their art pieces might be shared, exhibited, and disseminated with broad audiences in a deliberately queer-focused way. Moving forward in our collaborations, we seek to explore how diverse audiences engage, make-sense of, and are possibly moved to action from the consumption of queer, trans, and non-binary young people and pre-service teachers' visual texts, including zines. As a research team with the goal of sharing queer, trans, and non-binary youth zines and art as an intervention to disrupt their experiences of erasure and minimalization in school and society, we still seek to do better at listening to what they are telling us. 


\section{References}

Airton, L., \& Koecher, A. (2019). How to hit a moving target: 35 years of gender and sexual diversity in teacher education. Teaching and Teacher Education, 80, 190-204. http://dx.doi.org/10.1016/j.tate.2018.11.004

Buchanan, R. (2012). Zines in the classroom: Reading culture. The English Journal, 102(2), 71-77. https://www.jstor.org/stable/23365401

Burke, S. (2018, October 1). A beginner's guide to making zines. Vice. https://www.vice. com/en us/article/d3jxyj/how-to-make-a-zine-vgtl

Burkholder, C. (2016). We are HK too! Disseminating cellphilms in a participatory archive. In K. MacEntee, C. Burkholder, \& J. Schwab-Cartas (Eds.), What's a cellphilm? Integrating mobile phone technology into participatory visual research and activism (pp. 153-168). Sense Publishers.

Burkholder, C., \& MacEntee, K. (2016). Exploring the ethics of a participant-produced cellphilm archive: The complexities of dissemination. In D. Warr, M. Guillemin, S. Cox, \& J. Waycott (Eds.), Ethics and visual research methods: Theory, methodology and practice (pp. 211-224). Palgrave Macmillan.

Burkholder, C., \& Thorpe, A. (2019). Cellphilm production as posthuman research method to explore injustice with queer youth in New Brunswick, Canada. Reconceptualizing Educational Research Methodology, 10(2-3), 292-309. https:// doi.org/10.7577/rerm.3680

Chu, J. (1997). Navigating the media environment: How youth claim a place through zines. Social Justice, 24(3), 71-85. https://www.jstor.org/stable/29767022

Crawford, L. (2020, August 17). Five reasons I won't share washrooms with cisgender people. PLATFORM: Provocative, Timely, Diverse. https://www.platformspace. net/home/five-reasons-i-wont-share-washrooms-with-cisgender-people

Creasap, K. (2014). Zine-making as feminist pedagogy. Feminist Teacher, 24(3), 155168. https://doi.org/10.5406/femteacher.24.3.0155

Crenshaw, K. (1989). Demarginalizing the intersection of race and sex: A black feminist critique of antidiscrimination doctrine, feminist theory and antiracist politics. 
University of Chicago Legal Forum, 1989(1), 139-167. https://chicagounbound. uchicago.edu/uclf/vol1989/iss1/8

Dinkins, E. G., \& Englert, P. (2015). LGBTQ literature in middle school classrooms: Possibilities for challenging heteronormative environments. Sex Education, 15(4), 392-405. https://doi.org/10.1080/14681811.2015.1030012

Etengoff, C. (2015). Using zines to teach about gender minority experiences and mixmethods research. Feminist Teacher, 25(2-3), 211-218. https://doi.org/10.5406/ femteacher.25.2-3.0211

Gilbert, J. (2014). Sexuality in school: The limits of education. University of Minnesota Press.

Graff, C. M., \& Stufft, D. L. (2011). Increasing visibility for LGBTQ students: What schools can do to create inclusive classroom communities. Current Issues in Education, 14(1), 1-27.

Gubrium, A., \& Harper, K. (2013). Participatory visual and digital methods. Left Coast Press.

Hall, W. J., Witkemper, K. D., Rogers, G. K., Waters, E. M., \& Smith, M. R. (2018). Activating adult allies from a rural community on lesbian, gay, bisexual, transgender, and queer student issues in school using photovoice. Journal of Gay \& Lesbian Social Services, 30(1), 49-63. https://doi.org/10.1080/10538720.2017. $\underline{1408517}$

Halstead, J. M., \& Reiss, M. J. (2003). Values in sex education: From principles to practice. Routledge.

Hernández, M. R. N., González, P. I. R., \& Sánchez, S. V. (2013). Gender and constructs from the hidden curriculum. Creative Education, 4(1), 89-92. http://dx.doi. org/10.4236/ce.2013.412A2013

Jones, T. (2013). How sex education research methodologies frame GLBTIQ students. Sex Education, 13(6), 687-701. https://doi.org/10.1080/14681811.2013.806262

King, D. K. (2016). Multiple jeopardy, multiple consciousness: The context of a Black feminist ideology. In B. Landry (Ed.), Race, gender, and class: Theory and methods of analysis (pp. 36-57). Routledge. (Reprinted from "Multiple jeopardy, 
multiple consciousness: The context of a Black feminist ideology," 1988, Signs: Journal of Women in Culture and Society, 14[1], 42-72.)

Lymn, J. A. (2014). Queering archives: The practices of zines [Doctoral dissertation, University of Technology, Sydney]. Open Publications of UTS Scholars. http:// hdl.handle.net/10453/29211

MacEntee, K., Burkholder, C., \& Schwab-Cartas, J. (Eds.). (2016). What's a cellphilm? Integrating mobile phone technology into participatory visual research and activism. Sense Publishers.

Mitchell, C. (2011). Doing visual research. Sage.

Mitchell, C., De Lange, N., \& Moletsane, R. (2017). Participatory visual methodologies: Social change, community and policy. Sage.

Nairn, K., Munro, J., \& Smith, A. B. (2005). A counter-narrative of a "failed" interview. Qualitative Research, 5(2), 221-244. https://doi.org/10.1177/1468794105050836

Ng, C. K. Y., Haines-Saah, R. J., Knight, R. E., Shoveller. J. A., \& Johnson, J. L. (2019). "It's not my business": Exploring heteronormativity in young people's discourses about lesbian, gay, bisexual, transgender, and queer issues and their implications for youth health and wellbeing. Health, 23(1), 39-57. https://doi. org/10.1177/1363459317715776

O’Brien, E. (2012). Zines: A personal history. New England Review, 33(2), 89-99. https:// doi.org/10.1353/ner.2012.0037

Payne, E., \& Smith, M. (2014). The big freak out: Educator fear in response to the presence of transgender elementary school students. Journal of Homosexuality, 61(3), 399-418. https://doi.org/10.1080/00918369.2013.842430

Perez, H. (2005). You can have my brown body and eat it, too! Social Text, 3-4(84-85), 171-191. https://doi.org/10.1215/01642472-23-3-4 84-85-171

Peter, T., Taylor, C., \& Edkins, T. (2016). Are the kids all right? The impact of school climate among students with LGBT parents. Canadian Journal of Education, 39(1), 1-25. https://journals.sfu.ca/cje/index.php/cje-rce/article/view/2018 
Piepmeier, A. (2008). Why zines matter: Materiality and the creation of embodied community. American Periodicals, 18(2), 213-283. https://doi.org/10.1353/ amp.0.0004

Preston, J. (2017). Racial extractivism and white settler colonialism: An examination of the Canadian Tar Sands mega-projects. Cultural Studies, 31(2-3), 353-375. https://doi.org/10.1080/09502386.2017.1303432

Rands, K. E. (2009). Considering transgender people in education: A gendercomplex approach. Journal of Teacher Education, 60(4), 419-431. https://doi. org/10.1177/0022487109341475

Rose, G. (2012). Visual methodologies: An introduction to researching with visual materials (3rd ed.). Sage.

Rosenberg, J., \& Garofalo, G. (1998). Riot grrrl: Revolutions from within. Signs: Journal of Women in Culture and Society, 23(3), 809-841. https://www.jstor.org/ stable/3175311

Singh, A. A., \& Kosciw, J. G. (2017). Introduction to the special issue: School counselors transforming schools for lesbian, gay, bisexual, transgender, and queer (LGBTQ) students. Professional School Counseling, 20(1), 1-4. https://doi. org/10.5330/1096-2409-20.1a.1

Smith, A. (2010). Queer theory and native studies: The heteronormativity of settler colonialism. GLQ: A Journal of Lesbian and Gay Studies, 16(1-2), 41-68. https:// doi.org/10.1215/10642684-2009-012

Strear, M. M. (2015). Forecasting an inclusive future: Accessible school counseling strategies to deconstruct educational heteronormativity [Unpublished doctoral dissertation]. University of Northern Colorado. https:// digscholarship.unco.edu/dissertations/52/?utm_source=digscholarship. unco.edu $\% 2$ Fdissertations $\% 2$ F52\&utm medium=PDF\&utm campaign $=$ PDFCoverPages

Sturgeon, N. (2016). Ecofeminist natures: Race, gender, feminist theory and political action. Routledge. 
Szalacha, L. A. (2004). Educating teachers on LGBTQ issues: A review of research and program evaluations. Journal of Gay \& Lesbian Issues in Education, 4(1), 67-79. https://doi.org/10.1300/J367v01n04 07

Thompson, J. A. (2016). Intersectionality and water: How social relations intersect with ecological difference. Gender, Place \& Culture, 23(9), 1286-1301. https://doi.org/ $\underline{10.1080 / 0966369 X .2016 .1160038}$

Tuck, E., \& Wang, K. W. (Eds.). (2014). Youth resistance research and theories of change. Routledge.

Warner, M. (Ed.). (1993). Fear of a queer planet: Queer politics and social theory. University of Minnesota Press.

Wilson, M. N., Asbridge, M., \& Langille, D. B. (2018). School connectedness and protection from symptoms of depression in sexual minority adolescents attending school in Atlantic Canada. Journal of School Health, 88(3), 182-189. https://doi. org/10.1111/josh.12595 